\title{
Activation of two distinct MAPK pathways governs constitutive expression of matrix metalloproteinase-1 in human pancreatic cancer cell lines
}

\author{
HITOSHI ENDO ${ }^{1,4}$, TETSU WATANABE ${ }^{1}$, YOSHIHIKO SUGIOKA ${ }^{1,4}$, \\ MAKI NIIOKA $^{2}$, YUTAKA INAGAKI $^{1}$ and ISAO OKAZAKI ${ }^{1,3}$ \\ ${ }^{1}$ Department of Community Health, ${ }^{2}$ Teaching and Research Support Center, Tokai University \\ School of Medicine, Isehara, Kanagawa Prefecture 259-1193; ${ }^{3}$ Department of Internal Medicine, \\ Sanno Hospital, International University of Health and Welfare, Minatoku, Tokyo 107-0052, Japan
}

Received July 8, 2009; Accepted September 4, 2009

DOI: 10.3892/ijo_00000440

\begin{abstract}
Elevated matrix metalloproteinase-1 (MMP-1) expression is known to correlate with poor prognosis of pancreatic cancer. We investigated the molecular mechanisms of constitutive expression of MMP-1 in pancreatic cancer cell lines. Expression of MMP-1 mRNA and protein as well as its enzymatic activity were observed in three pancreatic cancer cell lines. Transient transfection assays of two MMP-1 promoter/luciferase constructs (full-length $4.4-\mathrm{kb}$ or proximal $0.6-\mathrm{kb}$ region) showed high levels of transcription in pancreatic cancer cells compared with nonMMP-1 producing cells. The $0.6-\mathrm{kb}$ promoter region of MMP-1 gene contained three activator protein-1 (AP-1) sites and the strong AP-1 activity was detected by electrophoretic mobility shift assays (EMSAs). In these cells, production and phosphorylation of c-Jun were commonly observed. Phosphorylated c-Jun NH2-terminal kinase (p-JNK) and activator transcription factor-2 (p-ATF-2) were also detected in two of the three cell lines. Phosphorylated extracellular
\end{abstract}

Correspondence to: Dr Isao Okazaki, Department of Community Health, Tokai University, School of Medicine, Isehara, Kanagawa Prefecture 259-1193, Japan

E-mail: iokazaki@iuhw.ac.jp

Present address: ${ }^{4}$ Department of Health Science, Asahikawa Medical College, Midorigaoka-Higashi 2-1-1-1, Asahikawa, Hokkaido 078-8510, Japan

Abbreviations: AP-1, activator protein-1; ATF-2, activator transcription factor-2; JNK, c-Jun NH2-terminal kinases; ERK, extracellular signal-regulated kinases; HCC, hepatocellular carcinoma; MAPK, mitogen-activated protein kinases; MMP, matrix metalloproteinase; MMPI, matrix metalloproteinase inhibition; PDA, pancreatic ductal adenocarcinoma

Key words: pancreatic cancer, matrix metalloproteinase-1, activator protein-1, extracellular signal-regulated kinases, c-Jun NH2-terminal kinases signal-regulated kinase ( $\mathrm{p}-\mathrm{ERK}$ ) was observed in one. The promoter activity, AP-1-binding activity and MMP-1 production were suppressed by a specific inhibitor of JNK or MEK. K-ras mutation, reported to be present in three cell lines used, is known to activate JNK and ERK pathways. Considering the facts together, our results revealed that activation of JNK/AP-1 or ERK/AP-1 pathway plays crucial roles in constitutive transactivation of MMP-1 in these cancer cells. This study contributes to provide new insights into strategies for inhibiting tumor cell invasion in pancreatic cancer.

\section{Introduction}

Pancreatic cancer is characterized by extensive local invasion, intense desmoplastic reaction, and early metastases to regional lymph nodes, peritoneum, liver, lung and other sites, and resistance to treatment with surgery, anti-cancer agents, radiation and others, with a poor prognosis $(1,2)$. Invasion and metastasis of malignant tumor cells are multi-step processes including the detachment of cells from the primary tumor, the degradation of structural barriers such as stromal extracellular matrix (ECM) and basement membrane, the spread to other organs with proliferation within the organ parenchyma (3). ECM degradation is mediated by the concerted action of several proteinases and their inhibitors, in which members of matrix metalloproteinases (MMPs), a disintegrin and metalloproteinases (ADAMs), a disintegrin and metalloproteinases with thrombospondin (ADAMTs) and tissue inhibitors of metalloproteinases (TIMPs) play crucial roles (4-6). The balance of these proteinases and inhibitors leads to biologically significant changes in the net proteolytic activity. In addition to their direct role of ECM degradation and cell invasion, MMPs have other functions that may mediate tumor proliferation and migration through the cleaving growth factors, their receptors and other growth factor-associated proteins (4-6). Although a large number of clinical trials for MMP Inhibitions (MMPI) were unsuccessful in the advanced pancreatic cancer patients with the distant organ metastasis $(4,7,8)$, recent reports show that synthetic MMP inhibitor is effective against pancreatic cancer invasion 
and metastasis in experimental model (9-14), and clinical trials $(15,16)$. Moreover, it has been suggested that selective MMPI, instead of MMPI targeting all MMPs, is effective for the treatment of early stage of cancer $(4,7)$.

The expression of MMP-1, which can specifically degrade type I and III collagens, was correlated with the poor prognosis in pancreatic cancer (17). The expression of MMP-1 was observed in $70 \%$ of the 70 cases of tumor tissue (18), and contrary to other MMPs, the expression of MMP-1 was observed in the early stage of pancreatic cancer (17). Considering that pancreatic cancer is usually surrounded by stromal ECM, mainly type I and III collagens $(19,20)$, it is conceivable to argue that pancreatic cancer cells release MMP-1 for their own advantage of proliferation and invasion.

We reported that MMP-1 expression is only detected in the early stage of hepatocellular carcinoma (HCC), welldifferentiated carcinoma, with stromal invasion of cancer cells (21). MMP-1 was also supposed to cause the proliferation of hepatocytes in the rat fibrotic liver infected with recombinant adenovirus harboring human MMP-1 gene (22). Our previous study showed that c-Jun is involved in constitutive expression of MMP-1 in a human hepatocellular carcinoma cell line through activation of the c-Jun $\mathrm{NH}_{2}$-terminal kinase (JNK) pathway (23). Although this may not be true in pancreatic cancer, the aims of this study is to clarify the role of mitogen-activated protein kinase (MAPKs) pathways in regulation of constitutive MMP-1 expression in human pancreatic ductal adenocarcinoma (PDA)-derived cell lines. Moreover, K-ras mutation has been reported to be closely related with the carcinogenesis of pancreatic cancer (24), and the three pancreatic cancer cell lines used in the present study had been proved to have a point mutation in codon 12 of K-ras gene (25). As MAPK pathway could be activated by K-ras mutation in most of pancreatic cancer $(26,27)$, new strategies are considered to block downstream pathways of Ras/MAPK system.

MAPKs are proline-directed protein kinases that mediate the signals of various extracellular stimuli on a wide array of biological process, such as cellular proliferation, embryonic cell differentiation and death $(28,29)$. Three signal-transduction pathways of mammalian MAPKs, that is, JNKs, extracellular signal-regulated kinases (ERKs) and p38MAPKs, induce the expression of MMP-1 in cancer cells (30-35). The analysis of MAPKs as the transcription factors inducing MMP-1 gene expression in pancreatic cancer cell has not been reported. The results indicate the activator protein-1 (AP-1) components are activated in these MMP-1-producing cell lines through activation of either JNK or ERK pathways. These MMP-1inducing mechanisms, activation of JNK or ERK pathway, identified in pancreatic cancer cells may be novel therapeutic targets for inhibition of cancer cell proliferation and invasion via Ras/MAPK system.

\section{Materials and methods}

Cell culture. Three human pancreatic cancer cell lines, AsPC-1 (36), Panc-1 (37) and MIA PaCa-2 (38) were used in this study. A human hepatocellular carcinoma cell line HCC-T (23) was used as a negative control of MMP-1 expression. Panc-1 and MIA PaCa-2 cells were cultured in
Dulbecco's modified Eagle's medium (Sigma Chemical Co., St. Louis, MO), while AsPC-1 and HCC-T cells were maintained in RPMI-1640 medium (Sigma). All cultured media were supplemented with $10 \%$ fetal bovine serum (FBS), $100 \mathrm{U} / \mathrm{ml}$ penicillin (Invitogen Life Technologies, Inc., Carlsbad, CA), $0.1 \mathrm{mg} / \mathrm{ml}$ streptomycin (Invitrogen), and non-essential amino acid (Invitrogen). These cells were cultured at $37^{\circ} \mathrm{C}$ and $5 \% \mathrm{CO}_{2}$ atmosphere.

Reagents. The selective MEK1/2 inhibitor U0126 was purchased from Cell Signaling Technology (Beverly, MA), and the selective JNKs inhibitor SP600125 was from Calbiochem-Novabiochem (San Diego, CA). Stock solution of each chemical reagent was prepared in dimethyl sulfoxide (DMSO) (Sigma) and diluted at least 1000-fold with culture media as a final working concentration.

RNA isolation and reverse transcription-PCR analysis. mRNA expression levels were determined by semi-quantitative RTPCR analysis as described previously $(23,39)$. Total RNA was isolated from cells using the GeneElute Mammalian Total RNA Kit (Sigma). The initial denaturation was at $94^{\circ} \mathrm{C}$ for $2 \mathrm{~min}$, followed by each cycle of reaction at $94^{\circ} \mathrm{C}$ for $30 \mathrm{sec}$, annealing at an adequate temperature (Table I) for $30 \mathrm{sec}$, and extension at $72^{\circ} \mathrm{C}$ for $30 \mathrm{sec}$, and terminated with an elongation step at $72^{\circ} \mathrm{C}$ for $7 \mathrm{~min}$. PCR products were separated on a $1.5 \%$ agarose gels and stained with ethidium bromide. Expression of glyceraldehyde 3-phosphate dehydrogenase (GAPDH) was monitored as a loading control.

Plasmids. A fragment encompassing the essential sequence for transcriptional activity of human MMP-1 promoter was amplified from genomic DNA isolated from HCC-T cells. HCC-T cells have not represented any mutation in transcription factor-binding elements within the promoter region. The human MMP-1 promoter/luciferase constructs of $4.4 \mathrm{~kb}$ full-length and the 5 '-deletion $0.6 \mathrm{~kb}$ have been described elsewhere (23).

Transient transfection and promoter activity assay. Duplicate cultured cells were plated at $60-\mathrm{mm}$ diameter dishes, and the MMP-1 promoter/luciferase constructs were transfected into AsPC-1, Panc-1, MIA PaCa-2 cells and HCC-T cells using the calcium phosphate-DNA co-precipitation method. Transfection efficiency was normalized by pRL-CMV vector (Promega, Madison, WI), which was used as an internal control. Six hours after transfection, the cells were treated with $7.5 \%$ glycerol for $90 \mathrm{sec}$, then incubated at $37^{\circ} \mathrm{C}$ for $48 \mathrm{~h}$. After the incubation, cells were washed twice with PBS, harvested and lysed with a passive lysis buffer. Firefly and Renilla luciferase activities were measured using Dual-Luciferase Reporter Assay System (Promega). Cell transfections and luciferase assays were repeated independently at least three times. The total amount of DNA was kept constant by the addition of the appropriate empty vector control, and the mean of the empty vector values for each cell lines was set arbitrarily at 100 to facilitate the graphical display of cell lines in the same chart.

Activation of MAPK and transcription factors. The cells were cultured in 100-mm diameter dishes. Cultured cells were 
Table I. Primers used for RT-PCR amplification.

\begin{tabular}{|c|c|c|c|c|c|}
\hline Gene name & & Nucleotide sequences & Annealing $\operatorname{Tm}\left({ }^{\circ} \mathrm{C}\right)$ & Cycles & Products (bp) \\
\hline MMP-1 & $\begin{array}{l}\text { sense } \\
\text { antisense }\end{array}$ & $\begin{array}{l}\text { 5'-GGT GCC CAGTGG TTG AAA AAT-3' } \\
\text { 5'-CAT CAC TTC TCC CCG AAT CGT-3' }\end{array}$ & 57 & 35 & 716 \\
\hline MMP-2 & $\begin{array}{l}\text { sense } \\
\text { antisense }\end{array}$ & $\begin{array}{l}\text { 5'-TCT TCC CTC GCA AGC CCA AGT-3' } \\
\text { 5'-ACA GTG GAC ATG GCG GTC TCA G-3' }\end{array}$ & 57 & 35 & 685 \\
\hline MMP-7 & $\begin{array}{l}\text { sense } \\
\text { antisense }\end{array}$ & $\begin{array}{l}\text { 5'-GTG GTC ACC TAC AGG ATC GTA-3' } \\
\text { 5'-CTG AAG TTT CTA TTT CTT TCT TGA-3' }\end{array}$ & 55 & 35 & 492 \\
\hline MMP-9 & $\begin{array}{l}\text { sense } \\
\text { antisense }\end{array}$ & $\begin{array}{l}\text { 5'-TGG GCT ACG TGA CCT ATG AC-3' } \\
\text { 5'-CAA AGG TGA GAA GAG AGG GC-3' }\end{array}$ & 59 & 35 & 200 \\
\hline MMP-13 & $\begin{array}{l}\text { sense } \\
\text { antisense }\end{array}$ & $\begin{array}{l}\text { 5'-GGG TTC CTG ATG TGG GTG AA-3' } \\
\text { 5'-GCT TTT GCC GGT GTA GGT GTA-3' }\end{array}$ & 56 & 35 & 461 \\
\hline TIMP-1 & $\begin{array}{l}\text { sense } \\
\text { antisense }\end{array}$ & $\begin{array}{l}\text { 5'-TTC TGC AAT TCC GAC CTC GTC-3' } \\
\text { 5'-GCA GTT TGC AGG GGA TGG ATA-3' }\end{array}$ & 58 & 30 & 385 \\
\hline TIMP-2 & $\begin{array}{l}\text { sense } \\
\text { antisense }\end{array}$ & $\begin{array}{l}\text { 5'-ACA GGA GCC GTC ACT TCT CTT GAT G-3' } \\
\text { 5'-CAT CAC TTC TCC CCG AAT CGT-3' }\end{array}$ & 59 & 35 & 405 \\
\hline c-jun & $\begin{array}{l}\text { sense } \\
\text { antisense }\end{array}$ & $\begin{array}{l}\text { 5'-CCT GTT GCG GCC CCG AAA CT-3' } \\
\text { 5'-ACC ATG CCT GCC CCG TTG AC-3' }\end{array}$ & 62 & 30 & 495 \\
\hline c-fos & $\begin{array}{l}\text { sense } \\
\text { antisense }\end{array}$ & $\begin{array}{l}\text { 5'-TTT GCC TAA CCG CCA CGA TGA T-3' } \\
\text { 5'-TTG CCG CTT TCT GCC ACC TC-3' }\end{array}$ & 62 & 30 & 500 \\
\hline GAPDH & $\begin{array}{l}\text { sense } \\
\text { antisense }\end{array}$ & $\begin{array}{l}\text { 5'-ACC ACA GTC CAT GCC ATC AC-3' } \\
\text { 5'-TCC ACC ACC CTG TTG CTG TA-3' }\end{array}$ & 62 & 25 & 452 \\
\hline
\end{tabular}

washed with ice-cold Tris-buffered saline [TBS $(25 \mathrm{mmol} / \mathrm{l}$ Tris- $\mathrm{HCl} \mathrm{pH} \mathrm{7.6,} 150 \mathrm{mmol} / \mathrm{l} \mathrm{NaCl})]$ and centrifuged at $1,500 \mathrm{x} \mathrm{g}$ for $10 \mathrm{~min}$. The cell pellets were lysed with lysis buffer [50 mmol/1 Tris-HCl (pH 7.4), 150 mmol/1 NaCl, 0.5\% Triton X-100, protease inhibitor (Sigma) and phosphatase inhibitor (Sigma)]. For protein extraction, the cells were lysed in a buffer containing complete protease inhibitor cocktail. Protein concentrations were measured using the DC Protein Assay Kit (Bio-Rad, Richmond, CA). Protein samples were denatured in a $2 \mathrm{X}$ Laemmli Sample Buffer (62.5 mmol/1 Tris-HCl, pH 6.8, 25\% glycerol, 2\% SDS, $0.01 \%$ bromophenol blue, $5 \%$ B-mercaptoethanol) for $10 \mathrm{~min}$ at $95^{\circ} \mathrm{C}$. Total protein $(30-50 \mu \mathrm{g})$ were separated under reducing conditions on either 8 or $10 \%$ SDS-polyacrylamide gel for $1.5 \mathrm{~h}$ at $4^{\circ} \mathrm{C}$, then were transferred onto polyvinylidene difluoride (PVDF) membrane (Immobilon-P; Millipore Corp., Bedford, MA) for $1 \mathrm{~h}$, by using the semi-dry transfer system. After blocking in TBS-0.05\% Tween-20 (TBS-T) with $5 \%$ non-fat dry milk or $3 \%$ bovine serum albumin (BSA) for $1.5 \mathrm{~h}$ at $25^{\circ} \mathrm{C}$, the membrane was incubated with rabbit anti-phospho-ERK1/2, anti-phospho-JNK1/2, antiphospho-p38MAPK, anti-phospho-c-Jun (Ser 63 and Ser 73) and anti-phospho-ATF-2 (Thr 69/71) antibodies (Cell Signaling Technology) for $3 \mathrm{~h}$ at room temperature. The membrane was then incubated with appropriate HRP-conjugated secondary antibodies for $1 \mathrm{~h}$, and washed with TBS-T. The immunoreactive protein was detected with ECL plus
(Amersham Pharmacia Biotech, San Francisco, CA) according to the manufacturer's instructions. Each membrane was stripped and reprobed with antibodies against B-actin (Sigma) to correct for differences in protein loading. These analyses were performed three times with different cell extracts.

Detection of MMP-1 protein. Western blot analysis was performed as described previously (23). Briefly, samples of $30 \mu \mathrm{l}$ of serum-free conditioned medium were incubated with $2 \mathrm{X}$ SDS sample buffer for $5 \mathrm{~min}$ at $100^{\circ} \mathrm{C}$. The samples were then electrophoresed on $10 \%$ SDS-polyacrylamide gel at $4^{\circ} \mathrm{C}$. After electrophoresis, samples were transferred onto a PVDF membrane. Detection of MMP-1 was performed using the ECL detection system (Amersham).

Zymographic analysis. Enzymatic activity of the MMP-1 was analyzed by using zymography as previously described (23). Briefly, $72 \mathrm{~h}$ after the cells were cultured in the absence of serum, the supernatant was collected and electrophoresed on SDS-polyacrylamide gels containing $0.1 \%$ gelatin (Sigma) at $4{ }^{\circ} \mathrm{C}$. After electrophoresis, gels were washed three times in $2.5 \%$ Triton $\mathrm{X}-100$ for $30 \mathrm{~min}$ to remove SDS, and incubated overnight at $37^{\circ} \mathrm{C}$ in substrate buffer $(50 \mathrm{mmol} / 1$ Tris- $\mathrm{HCl}, \mathrm{pH} 7.6$, containing $5 \mathrm{mmol} / \mathrm{C} \mathrm{CaCl}_{2}$ and $0.1 \%$ Triton $\mathrm{X}-100)$. Enzymatic activity was visualized by staining in $40 \%$ methanol/10\% glacial acetic acid containing $0.1 \%$ Coomassie Brilliant Blue R 250 (Bio-Rad) for $1 \mathrm{~h}$. 
A

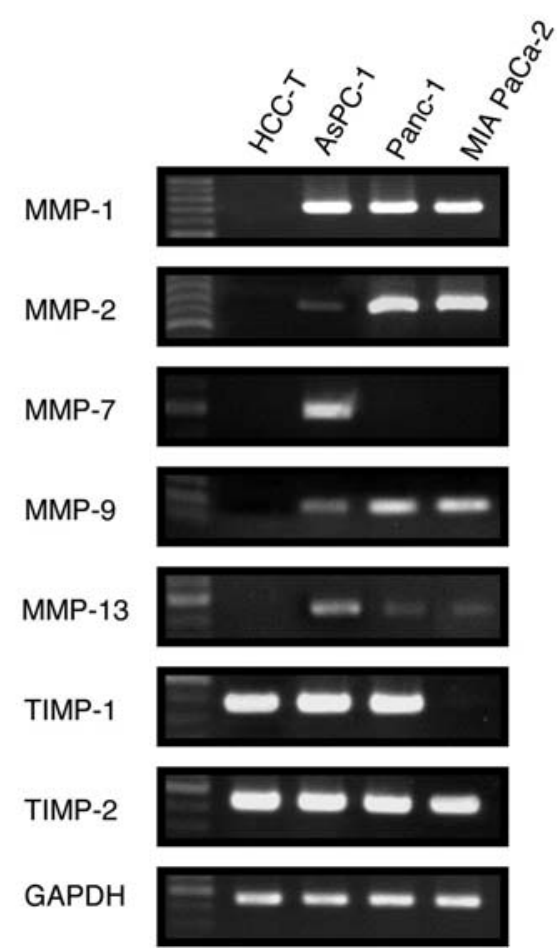

B

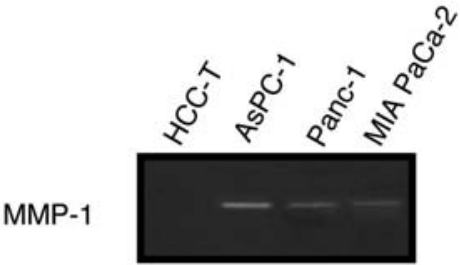

Figure 1. The constitutive expressions of MMP-1, other MMP and TIMP genes in human pancreatic cancer cell lines. (A) MMP-1, MMP-2, MMP-7, MMP-9, MMP-13, TIMP-1, TIMP-2 and GAPDH genes in HCC-T cells (hepatocellular carcinoma cell line), AsPC-1, Panc-1 and MIA PaCa-2 cells (pancreatic carcinoma cell lines) were detected by semi-quantitative RT-PCR analysis. After total RNA was extracted from these cells, $1 \mu \mathrm{g}$ of aliquots was amplified as described in Materials and methods. GAPDH gene was amplified as an internal control. (B) Enzymatic activity of MMP-1 in HCC-T cells and pancreatic cancer cells. Conditioned medium was collected from the cultured cell lines. Equal amount of protein from these cells were subjected to zymography analysis. Enzymatic activity of MMP-1 corresponds to $53 \mathrm{kDa}$. Results are representative of three independent experiments.

Electrophoretic mobility shift assays (EMSA). EMSA was performed as described previously (39). Briefly, nuclear protein/DNA complexes were subjected to electrophoresis in non-denaturing 5\% polyacrylamide gels containing $2 \%$ glycerol in $0.25 \%$ Tris-borate/EDTA buffer, and transferred to Hybond- $\mathrm{N}^{+}$nylon transfer membranes (Amersham Biosciences) for detection using the Light-Shift EMSA kit (Pierce) according to the manufacturer's protocol with minor modifications. An AP-1 probe was purchased from Panomics, Inc. (Redwood City, CA). The binding specificity was confirmed in each case by the addition of a 100 -fold molar excess of unlabeled oligonucleotide.

Statistical analysis. The data generated from at least three independent experiments and expressed as the mean \pm SD were analyzed by Mann-Whitney U-test; P-values <0.05 were considered statistically significance.

\section{Results}

Constitutive expression of MMP-1, other MMPs and TIMPs in pancreatic cancer cell lines. Three pancreatic cancer cell lines, AsPC-1, Panc-1 and MIA PaCa-2, were examined for the expression of MMP- and TIMP-mRNAs by semiquantitative RT-PCR analysis. Three cell lines examined here were established from PDA. Though they were different morphologically, the differentiation stage was poor in all three cell lines (36-38). In all of them, definite expression of MMP-1 gene was detected without exogenous stimulus
(Fig. 1A). Expression of MMP-2, MMP-7, MMP-9 and MMP-13 mRNA was also observed in various levels. In contrast, MMP expressions were not detected in HCC-T cells. TIMP-1 mRNA was detected in AsPC-1, Panc-1 and HCC-T cells, but not in MIA PaCa- 2 cells. TIMP-2 mRNA was expressed in all cell lines. The enzymatic activity of MMP-1 was also confirmed in all pancreatic cancer cell lines by zymography analysis (Fig. 1B). These results suggest that the constitutive expression of MMP-1 is observed in these three pancreatic cancer cell lines.

High transcriptional activity of full-length $(4.4 \mathrm{~kb})$ and proximal (0.6 kb) MMP-1 promoter in pancreatic cancer cells. To investigate the mechanisms of the constitutive transactivation of MMP-1 gene in pancreatic cancer cells, we first examined the activity of $4.4 \mathrm{~kb}$ (full-length) MMP-1 promoter construct, which contained the entire human MMP-1 promoter region using a transient transfection assays. The promoter activities in those pancreatic cancer cells were 4-6 times higher than that in non-MMP-1-producing HCC-T cells (Fig. 2A). There was no difference in MMP-1 promoter activity among three pancreatic cancer cell lines.

To further elucidate the region containing the element of constitutive expression, we examined a proximal $0.6-\mathrm{kb}$ promoter of MMP-1 gene. Similar to the results with the $4.4-\mathrm{kb}$ region, the transcriptional activities of $0.6-\mathrm{kb}$ promoter in MMP-1 producing three pancreatic cancer cells were significantly higher than that in non-MMP-1-producing HCC-T cells (Fig. 2B). Three AP-1-binding sites were 

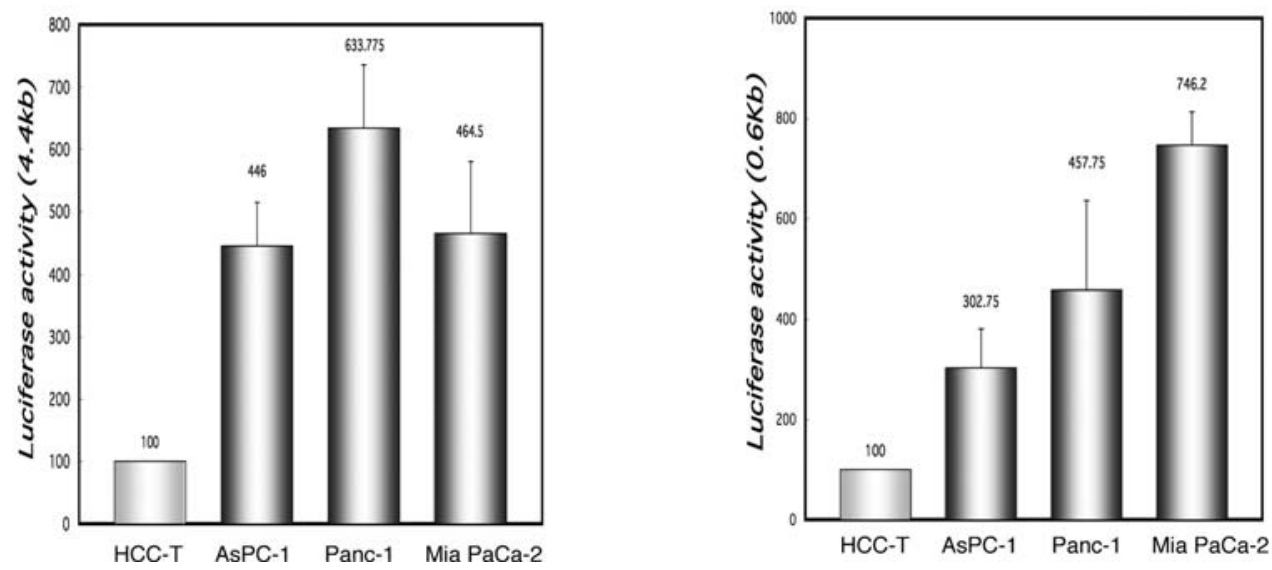

Figure 2. Basal transcriptional activities of MMP-1 promoters in pancreatic cancer cells. Each cell line was transfected with the human MMP-1 promoter/luciferase reporter gene constructs $[4.4 \mathrm{~kb}(\mathrm{~A})]$ and 5 '-delation constructs $[0.6 \mathrm{~kb}(\mathrm{~B})]$ promoter, respectively, with the pRL-CMV luciferase constructs. After transfection, cells were incubated for $48 \mathrm{~h}$. Relative luciferase activities (mean \pm SD) were normalized for pRL-CMV activity and calculated as a percentage of promoter activity in these cells. The values shown indicate the ratio of luciferase activities in HCC-T cells and in each pancreatic cancer cells, each run in duplicate. Luciferase activity of HCC-T cells was defined as 100\%. Transfection assays were performed independently three to five times.

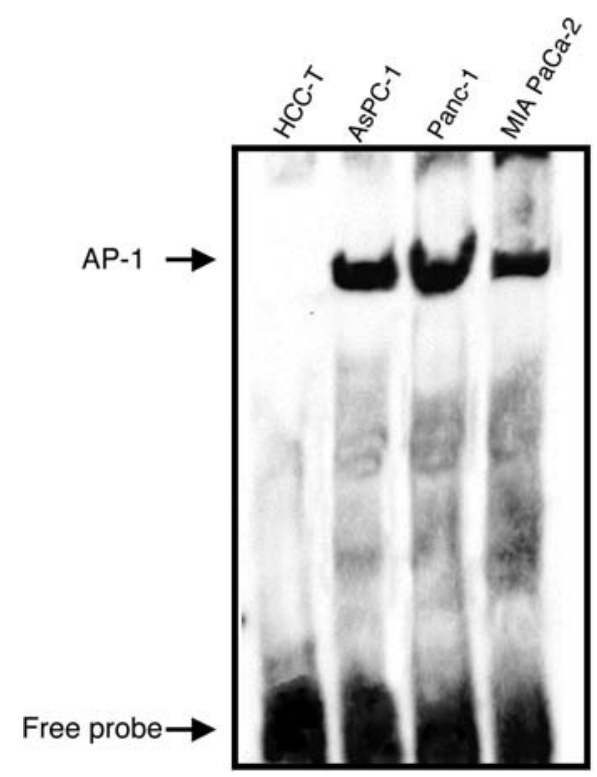

Figure 3. Constitutive activation of AP-1 transcription factor in pancreatic cancer cells. Nuclear proteins were extracted from untreated cells and analyzed for AP-1 binding by EMSA. Extracts were incubated with a biotinylated double-stranded AP-1 probe. AP-1-binding complexes were detected only in pancreatic cancer cells.

located within the 0.6-kb promoter region (40), suggesting that $\mathrm{AP}-1$ transcription factor is responsible for the constitutive expression of MMP-1 gene in pancreatic cancer cells.

Strong AP-1-binding activity of the MMP-1 promoter region in pancreatic cancer cells. The transient transfection assays indicated that AP-1 sites are involved in constitutive transactivation of MMP-1 gene in pancreatic cancer cells. To examine this further, we performed EMSA with a labeled AP-1 probe. As shown in Fig. 3, strong AP-1-binding activity was observed in three pancreatic cancer cells, but not in
HCC-T cells. Specificity of the binding was ascertained by competition assays using unlabeled wild-type and mutant AP-1 oligonucleotides (data not shown).

Distinct MAPK-signaling pathways contribute to the activation of AP-1 transcription factors without stimulation. The results of transfection assays and EMSA analysis showed that AP-1 transcription factor contributes to the constitutive MMP-1 expression in pancreatic cancer cells. The AP-1 transcription factor can be formed by Jun, Fos and ATF family members $(41,42)$. To investigate the AP-1 components in MMP-1 producing cells, we first examined c-jun and c-fos expression by semiquantitative RT-PCR. Expression of c-jun gene was observed in three pancreatic cancer cell lines, but not in HCC-T cells (Fig. 4A). In contrast, $\mathrm{c}$-fos gene expression was not detected in any of the cell lines.

Next, we examined the production of c-Jun, phosphorylated c-Jun (Ser 63 and Ser 73) and phosphorylated ATF-2 (Thr 69 and Thr 71) proteins in these cell lines. c-Jun production was detected in all pancreatic cancer cells, but not in HCC-T cells (Fig. 4B). Furthermore, phosphorylated c-Jun was also detected using both anti-phospho-Ser 63 and antiphospho-Ser 73 antibodies in all of the pancreatic cancer cells. In contrast, phosphorylated ATF-2 (Thr 69/71) was observed in AsPC-1 and Panc-1 cells, but not in MIA PaCa-2 cells (Fig. 4C).

c-Jun, c-Fos and ATF-2 are activated by MAPK (JNK, ERK and p38) as downstream substrates $(29,41,43)$, and activation of the MAPK cascades has been shown to be essential for the activation of transcriptional factor AP-1 (42). Therefore, we analyzed activation status of each MAPK in these cell lines by Western blot analysis using phosphospecific antibodies. As shown in Fig. 4D, phosphorylated JNK was observed in AsPC-1 and Panc-1 cells, whereas activation of ERK was detected in MIA PaCa-2 cells. In contrast, neither JNK or ERK phosphorylation was observed 
A
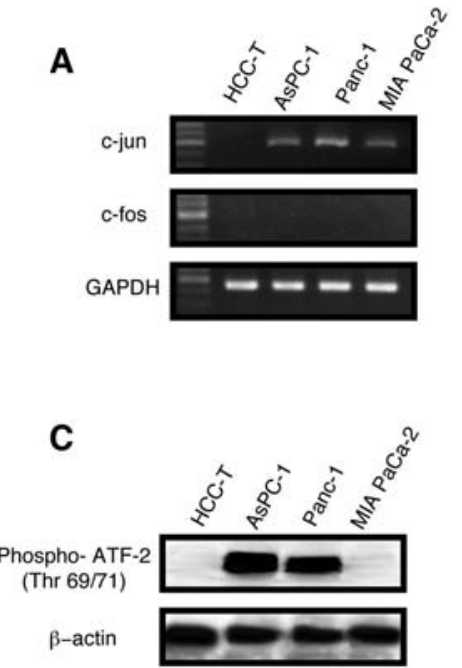

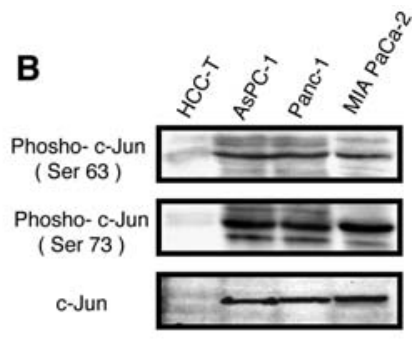

D

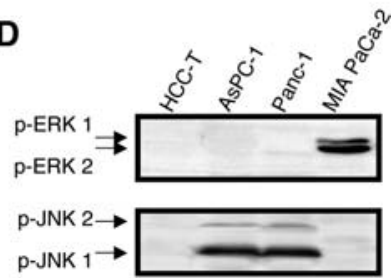

Figure 4. Expression of AP-1 transcription factor in pancreatic cancer cells. (A) Expressions of c-jun, c-fos and GAPDH genes were examined by semiquantitative RT-PCR. Constitutive expression of c-jun mRNA was observed in pancreatic cancer cells, but not HCC-T cells without stimulus. c-fos mRNA was not observed in any of the cell lines. GAPDH gene expression was analyzed as a loading control. (B) Western blot analysis of whole cell extracts were subjected to using c-Jun and phosphospecific c-Jun antibodies (Ser 63 and Ser 73). Expression of c-Jun, phosphorylated c-Jun at Ser 63 and Ser 73 were detected in three pancreatic cancer cell lines, but not in HCC-T cells. The anti-c-Jun blot was stripped and reprobed with anti-phospho-c-Jun antibodies. (C) Phosphorylated ATF-2 at both Thr 69 and Thr 71 was detected by Western blot analysis using phosphospecific ATF-2 antibody. B-actin production was examined as the loading control. (D) Constitutive activation of either ERK or JNK was detected in pancreatic cancer cells. Whole cell extracts were prepared and subjected by Western blot analysis using phosphorylation of ERK1/2 (p-ERK1/2), phosphorylation of JNK1/2 (p-JNK1/2) antibodies.

A

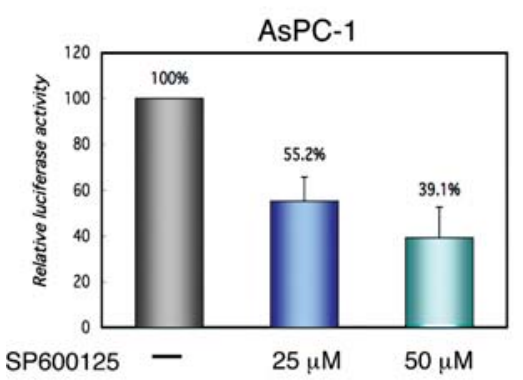

B

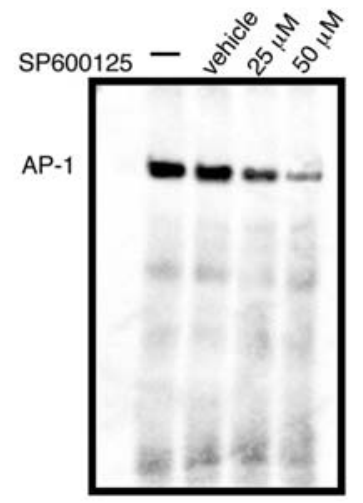

C

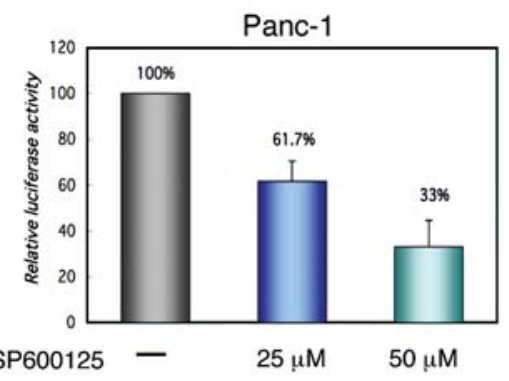

D

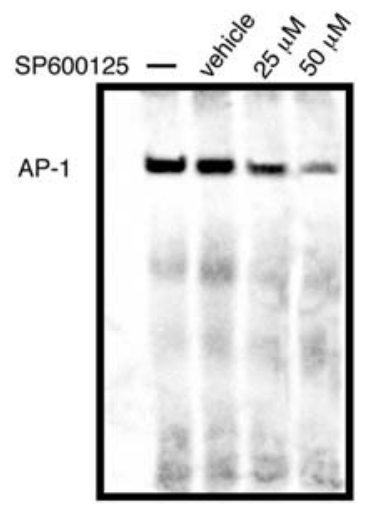

E

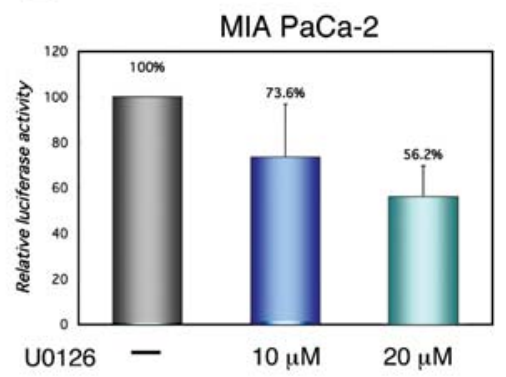

$\mathbf{F}$

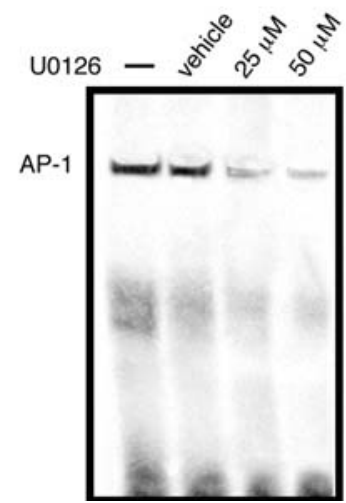

Figure 5. Effect of kinase inhibitor on 0.6-kb MMP-1 promoter activity and AP-1 binding. Inhibition of MMP-1 promoter activities by JNK specific inhibitor (SP600125) was investigated in constitutively MMP-1-expressing AsPC-1 and Panc-1 cells. Similarly, inhibition of MMP-1 promoter activities by MEK/ERK-specific inhibitor (U0126) was also examined in constitutively MMP-1-expressing MIA PaCa-2 cells. (A and B) Treatment with SP600125 showed a significantly decreased promoter activity and AP-1 binding in AsPC-1 cells. (C and D) Treatment of Panc-1 cells with SP600125 showed a significant inhibition of promoter activity and AP-1 binding. (E and F) Treatment with U0126 showed a significantly decreased promoter activity and AP-1 binding in MIA PaCa-2 cells. Before transfection, these cells were cultured for $24 \mathrm{~h}$ in the presence of SP600125 ( 25 and $50 \mu \mathrm{mol} / 1$; JNK inhibitor), or U0126 (10 and $20 \mu \mathrm{mol} / 1$; MEK/ERK inhibitor). After transfection with human MMP-1 promoter/luciferase reporter gene constructs $(0.6 \mathrm{~kb})$ together with pRL$\mathrm{CMV}$, these cells were incubated for $48 \mathrm{~h}$ in the presence of the same concentrations of each inhibitor. Transfection assays were performed independently 3-5 times, each run in duplicate. In EMSA, AsPC-1 and Panc-1 cells were treated with SP600125 for 48 h. MIA PaCa- 2 cells were treated with U0126 for $48 \mathrm{~h}$ before the nuclear proteins extraction. After incubating for $48 \mathrm{~h}$, nuclear proteins were incubated AP-1 DNA probe, as described in Materials and methods. Statistical significance was noted as ${ }^{*} \mathrm{P}<0.05 ;{ }^{* *} \mathrm{P}<0.01$. 
A

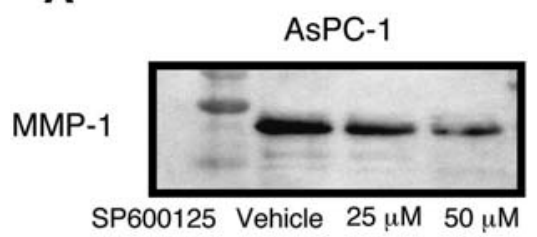

B
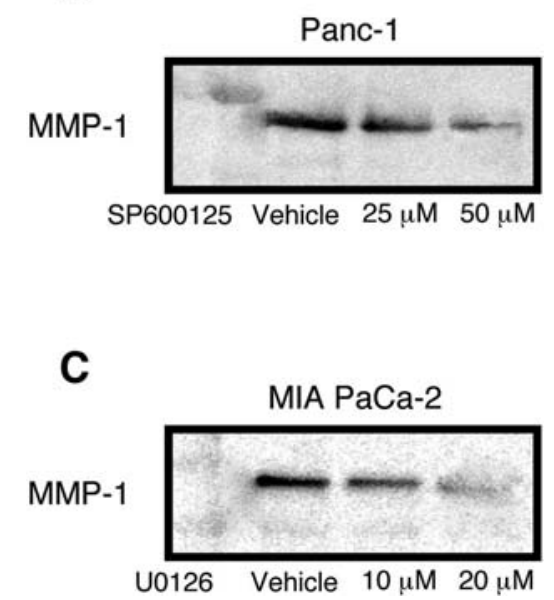

Figure 6. The kinase inhibitor decreased the production of MMP-1 protein. (A and B) AsPC-1 and Panc-1 cells were treated with SP600125 in serumfree media for $72 \mathrm{~h}$. Condition medium was used to examine the production of MMP-1 by Western blot analysis. (C) MIA PaCa- 2 cells were treated with U0126 in serum-free media for $72 \mathrm{~h}$, and the culture media were subjected to Western blot analysis for MMP-1. Treatment of these cells with each kinase inhibitor showed suppression of MMP-1 in a dose-dependent manner. Assays were performed independently three times.

in HCC-T cells. Phosphorylation of p38MAPK was not detected in any of the cell lines (data not shown). It is therefore likely that continuous activation of either JNK or ERK causes phosphorylation of c-Jun and/or ATF-2, and is closely associated with the constitutive expression of MMP-1 gene in pancreatic cancer cells without external stimulation factors.

Effects of kinase inhibitors on MMP-1 promoter activity and $A P-1$ transcription factor. In order to confirm the contribution of these MAPK pathways to constitutive expression of MMP-1 gene in pancreatic cancer cells, we performed transient transfection of these cells with $0.6-\mathrm{kb}$ promoter/ luciferase construct and treatment with JNK specific inhibitor SP600125 or MEK-ERK specific inhibitor U0126. In AsPC-1 and Panc-1 cells, the promoter activity was dramatically decreased by the treatment of SP600125 in a dose-dependent manner. The $0.6-\mathrm{kb}$ promoter activity was reduced by approximately 60 and $70 \%$ in AsPC-1 and Panc-1, respectively, after incubation with $50 \mu \mathrm{mol} / 1 \mathrm{SP} 600125$ (Fig. 5A and C). On the other hand, the promoter activity in MIA PaCa- 2 cells was decreased by treatment of U0126 in a dose-dependent manner, which was reduced by approximately $45 \%$ with $20 \mu \mathrm{mol} / \mathrm{l}$ of the inhibitor (Fig. 5E).

Next, to determine whether the decrease in promoter activity by treatment with each kinase inhibitor was the result of suppression of AP-1-binding activity, we analyzed the AP-1 binding by EMSA using nuclear extracts prepared from cells treated with each kinase inhibitor. AsPC-1 and Panc-1 cells were treated with SP600125, while MIA PaCa-2 cells were treated with U0126. Consistent with the results of transfection assays, EMSA also showed that dose-dependent suppression of AP-1 binding was observed in all cell lines upon treatment with each kinase inhibitor (Fig. 5B, D and F). These results revealed that activation of AP-1 through the JNK/AP-1 or ERK/AP-1 pathway regulates the constitutive expression of MMP-1 gene in pancreatic cancer cells.

Effects of kinase inhibitor on production of MMP-1 protein. Finally, we investigated whether JNK or ERK pathway regulates not only the constitutive transactivation but also the MMP-1 production. In AsPC-1 and Panc-1 cells, the production of MMP-1 protein was decreased dramatically with SP600125 in a dose-dependent manner (Fig. 6A and B). In MIA PaCa- 2 cells, MMP-1 protein was also decreased with U0126 in a dose-dependent manner (Fig. 6C). These results provide evidence that activation of either JNK or ERK plays a crucial role in production of MMP-1 in pancreatic cancer cells.

\section{Discussion}

The three pancreatic cancer cell lines used in the present study were all derived from human PDA, although AsPC-1 cells were established from ascites. Morphologically they were not the same, but seemed to be undifferentiated cancer cells microscopically (36-38). Tumorigenicity was proven in athymic nude mice in all three cell lines (36-38). The original paper on AsPC-1 reported that its xenograft showed mucinproducing tumor with the positive staining of carcinoembryonic antigen fluorescin in some portion of well-differentiated adenocarcinoma (36). Although some difference between the three cancer cell lines had been described (36-38), we cannot observe differences in differentiation among them.

The present study revealed constitutive expression of MMP-1 gene and enzymatic activity in the three pancreatic cancer cell lines without stimulus. Kitamura et al reported on development of cell lines from human PDA constitutively expressing many MMPs including MMP-1 (44), but they did not analyze the mechanisms of constitutive gene expression of MMP-1. No other reports exist on the constitutive expression of MMP-1 gene and enzymatic activity in pancreatic cancer cell lines.

Our study revealed that transient transfection assays of full-length MMP-1 promoter revealed that the promoter activity in pancreatic cancer cells is higher than that in MMP-1 non-producing HCC-T cells. Likewise, transient transfection assays with the $0.6-\mathrm{kb}$ constructs $(-522 /+72)$ also showed higher promoter activity. There are three AP-1 binding-sites at $-436,-181$ and -72 bp within the $0.6-\mathrm{kb}$ promoter region (Genbank accession number AF023338) (40). For the basal and the TPA, IL-1ß and other cytokines-induced transcriptional enhancement of MMP-1 gene, activation of AP-1binding motif in MMP-1 promoter region is indispensable $(40,45)$. Furthermore, our results of promoter assays were reinforced by EMSA using the AP-1 sequences as a probe, which showed definite protein-DNA complexes in pancreatic cancer cells. Therefore, these results raised a possibility that 
activation of AP-1 is an essential step in the constitutive expression of MMP-1 gene in pancreatic cancer cells.

In the present experiments, our results showed that either phosphorylated JNK or phosphorylated ERK were detected in MMP-1-producing pancreatic cancer cells. In addition, the definite signals of total and phosphorylated c-Jun were detected in three pancreatic cancer cells. On the other hand, phosphorylated ATF-2 was observed in AsPC-1 and Panc-1 cells. ATF-2 as well as c-Jun is known as a target of JNK, and ATF-2 is activated by phosphorylation at Thr 69 and Thr 71 (46,47). Therefore, we speculate that constitutive transactivation of MMP-1 gene is regulated through the JNK/AP-1 or ERK/AP-1 pathway in pancreatic cancer cells. Experiments using kinase inhibitors confirmed this hypothesis. In transient transfection assays, JNK specific inhibitor SP600125 reduced the MMP-1 promoter activity in AsPC-1 and Panc-1 cells, whereas MEK-ERK-specific inhibitor U0126 decreased the MMP-1 promoter activity in MIA $\mathrm{PaCa}-2$ cells. Furthermore, kinase inhibitors reduced the AP-1binding activity as well as production of MMP-1 protein in three pancreatic cancer cells. Collectively, our observations revealed novel molecular mechanisms in which the constitutive expression of MMP-1 gene regulated by activation of distinct MAPK pathways in pancreatic cancer cells.

Several gene mutations have been identified in various type of cancer, and these mutations lead to uncontrolled proliferation and invasion. Most of pancreatic cancers harbor a point mutation of $\mathrm{K}$-ras oncogene and this mutation is known to occur in a relatively early stage in pancreatic carcinogenesis (24). Activated ras stimulates Raf/MEKERK and/or Rho/ROCK/JNK pathways and regulates the transcription of AP-1-mediated genes $(26,27,48,49)$. All three pancreatic cancer cell lines used in the present study have been reported to have a point mutation in codon 12 of K-ras gene: a GGT-GAT substitution (Gly to Asp) (25). Therefore, activation of ERK or JNK pathways is most likely the result of K-ras gene mutation, which provokes the constitutive expression of MMP-1 through the activation of AP-1 proteins. Considering MAPK pathways may be activated by K-ras mutation in the early stage of most pancreatic cancers, our targets of anti-cancer therapy should be set for blocking the pathways of Ras/JNK/AP-1/MMP-1 and/or Ras/ERK/AP-1/MMP-1. Although three cancer cell lines used in the present study might not represent all pancreatic cancer, we believe that our findings provide important clues for the design of future therapies for human pancreatic cancer, that is, to use selective inhibitors against MMP-1 expression even in the early stage in combination with surgical resection.

In conclusion, this is the first report to show that two distinct MAPK pathways regulate constitutive MMP-1 expression in human pancreatic cancer cells. No other reports have shown the analysis between MMP-1 expression and MAPK in PDA cell lines.

\section{Acknowledgments}

This work was supported in part by a Grant-in-Aid from the Ministry of Education, Culture, Sports, Science and Technology, Japan (IO, 13557034) and Tokai University School of Medicine Research Aid (HE).

\section{References}

1. Warshaw AL and Fernandez-del Castillo C: Pancreatic carcinoma. N Engl J Med 326: 455-465, 1992.

2. Pliarchopoulou K and Pectasides D: Pancreatic cancer: current and future treatment strategies. Cancer Treat Rev 35: 431-436, 2009.

3. Steeg PS: Tumor metastasis: mechanistic insights and clinical challenges. Nat Med 12: 895-904, 2006.

4. Egeblad M and Werb Z: New functions for the matrix metalloproteinases in cancer progression. Nat Rev Cancer 2: 161-174, 2002.

5. Nabeshima K, Inoue T, Shimao Y and Sameshima T: Advances in matrix metalloproteinases (MMPs), membrane-type MMPs, and a disintegrin and metalloproteinase and their roles in cellular interaction and migration. In: Extracellular Matrix and the Liver-approach to Gene Therapy. Okazaki I, Ninomiya Y, Friedman SL and Tanikawa K (eds). Academic Press, New York, pp251-275, 2003.

6. Mochizuki S and Okada Y: ADAMs in cancer cell proliferation and progression. Cancer Sci 98: 621-628, 2007.

7. Overall CM and Lopez-Otin C: Strategies for MMP inhibition in cancer: innovations for the post-trial era. Nat Rev Cancer 2: 657-672, 2002.

8. Bloomston M, Zervos EE and Rosemurgy AS 2nd: Matrix metalloproteinases and their role in pancreatic cancer: a review of preclinical studies and clinical trials. Ann Surg Oncol 9: 668-674, 2002.

9. Jimenez RE, Hartwig W, Antoniu BA, Compton CC, Warshaw AL and Fernandez-Del Castillo C: Effect of matrix metalloproteinase inhibition on pancreatic cancer invasion and metastasis: an additive strategy for cancer control. Ann Surg 231: 644-654, 2000.

10. Zervos EE, Shafii AE and Rosemurgy AS: Matrix metalloproteinase (MMP) inhibition selectively decreases type II MMP activity in a murine model of pancreatic cancer. J Surg Res 81: 65-68, 1999.

11. Haq M, Shafii A, Zervos EE and Rosemurgy AS: Addition of matrix metalloproteinase inhibition to conventional cytotoxic therapy reduces tumor implantation and prolongs survival in a murine model of human pancreatic cancer. Cancer Res 60: 3207-11, 2000.

12. Sato N, Maehara N, Su GH and Goggins M: Effects of 5-aza-2'deoxycytidine on matrix metalloproteinase expression and pancreatic cancer cell invasiveness. J Natl Cancer Inst 95: 327-330, 2003.

13. Kilian M, Gregor JI, Heukamp I, et al: Matrix metalloproteinase inhibitor RO 28-2653 decreases liver metastasis by reduction of MMP-2 and MMP-9 concentration in BOP-induced ductal pancreatic cancer in Syrian Hamsters: inhibition of matrix metalloproteinases in pancreatic cancer. Prostaglandins Leukot Essent Fatty Acids 75: 429-434, 2006.

14. Kapischke M, Fischer T, Tiessen K, et al: Characterisation of a novel matrix metalloproteinase inhibitor on pancreatic adenocarcinoma cells in vitro and in an orthotopic pancreatic cancer model in vivo. Int J Oncol 32: 273-282, 2008.

15. Bramhall SR, Rosemurgy A, Brown PD, Bowry C and Buckels JA: Marimastat as first-line therapy for patients with unresectable pancreatic cancer: a randomized trial. J Clin Oncol 19: 3447-3455, 2001.

16. Bramhall SR, Schulz J, Nemunaitis J, Brown PD, Baillet M and Buckels JA: A double-blind placebo-controlled, randomised study comparing gemcitabine and marimastat with gemcitabine and placebo as first line therapy in patients with advanced pancreatic cancer. Br J Cancer 87: 161-167, 2002.

17. Ito T, Ito M, Shiozawa J, Naito S, Kanematsu T and Sekine I: Expression of the MMP-1 in human pancreatic carcinoma: relationship with prognostic factor. Mod Pathol 12: 669-674, 1999.

18. Yamamoto $\mathrm{H}$, Itoh $\mathrm{F}$, Iku $\mathrm{S}$, et al: Expression of matrix metalloproteinases and tissue inhibitors of metalloproteinases in human pancreatic adenocarcinomas: clinicopathologic and prognostic significance of matrilysin expression. J Clin Oncol 19: 1118-1127, 2001.

19. Gress TM, Muller-Pillasch F, Lerch MM, Friess H, Buchler M and Adler G: Expression and in-situ localization of genes coding for extracellular matrix proteins and extracellular matrix degrading proteases in pancreatic cancer. Int J Cancer 62: 407-413, 1995.

20. Yen TW, Aardal NP, Bronner MP, et al: Myofibroblasts are responsible for the desmoplastic reaction surrounding human pancreatic carcinomas. Surgery 131: 129-134, 2002. 
21. Okazaki I, Wada N, Nakano M, et al: Difference in gene expression for matrix metalloproteinase- 1 between early and advanced hepatocellular carcinomas. Hepatology 25: 580-584, 1997.

22. Iimuro $\mathrm{Y}$, Nishio T, Morimoto T, et al: Delivery of matrix metalloproteinase-1 attenuates established liver fibrosis in the rat. Gastroenterology 124: 445-458, 2003.

23. Sugioka Y, Watanabe T, Inagaki Y, et al: c-Jun NH2-terminal kinase pathway is involved in constitutive matrix metalloproteinase-1 expression in a hepatocellular carcinoma-derived cell line. Int J Cancer 109: 867-874, 2004.

24. Bardeesy N and DePinho RA: Pancreatic cancer biology and genetics. Nat Rev Cancer 2: 897-909, 2002.

25. Berrozpe G, Schaeffer J, Peinado MA, Real FX and Perucho M: Comparative analysis of mutations in the p53 and K-ras genes in pancreatic cancer. Int J Cancer 58: 185-191, 1994.

26. Denhardt DT: Signal-transducing protein phosphorylation cascades mediated by Ras/Rho proteins in the mammalian cell: the potential for multiplex signalling. Biochem J 318: 729-747, 1996.

27. Chang F, Steelman LS, Shelton JG, et al: Regulation of cell cycle progression and apoptosis by the Ras/Raf/MEK/ERK pathway (Review). Int J Oncol 22: 469-480, 2003.

28. Cross TG, Scheel-Toellner D, Henriquez NV, Deacon E, Salmon M and Lord JM: Serine/threonine protein kinases and apoptosis. Exp Cell Res 256: 34-41, 2000.

29. Johnson GL and Lapadat R: Mitogen-activated protein kinase pathways mediated by ERK, JNK, and p38 protein kinases. Science 298: 1911-1912, 2002.

30. Johansson N, Ala-aho R, Uitto V, et al: Expression of collagenase-3 (MMP-13) and collagenase-1 (MMP-1) by transformed keratinocytes is dependent on the activity of p38 mitogenactivated protein kinase. J Cell Sci 113: 227-235, 2000

31. Ishii Y, Ogura T, Tatemichi M, Fujisawa H, Otsuka F and Esumi H: Induction of matrix metalloproteinase gene transcription by nitric oxide and mechanisms of MMP-1 gene induction in human melanoma cell lines. Int J Cancer 103: 161-168, 2003.

32. Tower GB, Coon CC, Benbow U, Vincenti MP and Brinckerhoff CE: Erk 1/2 differentially regulates the expression from the $1 \mathrm{G} / 2 \mathrm{G}$ single nucleotide polymorphism in the MMPpromoter in melanoma cells. Biochim Biophys Acta 1586: 265-274, 2002

33. Davidson B, Givant-Horwitz V, Lazarovici P, et al: Matrix metalloproteinases (MMP), EMMPRIN (extracellular matrix metalloproteinase inducer) and mitogen-activated protein kinases (MAPK): co-expression in metastatic serous ovarian carcinoma. Clin Exp Metastasis 20: 621-631, 2003.

34. Huntington JT, Shields JM, Der CJ, et al: Overexpression of collagenase 1 (MMP-1) is mediated by the ERK pathway in invasive melanoma cells: role of BRAF mutation and fibroblast growth factor signaling. J Biol Chem 279: 33168-33176, 2004.

35. Junttila MR, Ala-Aho R, Jokilehto T, et al: p38alpha and p38delta mitogen-activated protein kinase isoforms regulate invasion and growth of head and neck squamous carcinoma cells. Oncogene 26: 5267-5279, 2007.
36. Chen WH, Horoszewicz JS, Leong SS, et al: Human pancreatic adenocarcinoma: in vitro and in vivo morphology of a new tumor line established from ascites. In Vitro 18: 24-34, 1982.

37. Lieber M, Mazzetta J, Nelson-Rees W, Kaplan M and Todaro G: Establishment of a continuous tumor-cell line (panc-1) from a human carcinoma of the exocrine pancreas. Int J Cancer 15: 741-747, 1975

38. Yunis AA, Arimura GK and Russin DJ: Human pancreatic carcinoma (MIA PaCa-2) in continuous culture: sensitivity to asparaginase. Int J Cancer 19: 218-235, 1977.

39. Endo H, Sugioka Y, Nakagi Y, Saijo Y and Yoshida T: A novel role of the NRF2 transcription factor in the regulation of arsenitemediated keratin 16 gene expression in human keratinocytes. Environ Health Perspect 116: 873-879, 2008.

40. Rutter JL, Benbow U, Coon CI and Brinckerhoff CE: Cell-type specific regulation of human interstitial collagenase-1 gene expression by interleukin- 1 beta (IL-1 beta) in human fibroblasts and BC-8701 breast cancer cells. J Cell Biochem 66: 322-336, 1997.

41. Morooka H, Bonventre JV, Pombo CM, Kyriakis JM and Force T: Ischemia and reperfusion enhance ATF-2 and c-Jun binding to cAMP response elements and to an AP-1 binding site from the c-jun promoter. J Biol Chem 270: 30084-30092, 1995.

42. Eferl R and Wagner EF: AP-1: a double-edged sword in tumorigenesis. Nat Rev Cancer 3: 859-868, 2003

43. Pulverer BJ, Kyriakis JM, Avruch J, Nikolakaki E and Woodgett JR: Phosphorylation of c-jun mediated by MAP kinases. Nature 353: 670-674, 1991

44. Kitamura N, Iwamura T, Taniguchi S, et al: High collagenolytic activity in spontaneously highly metastatic variants derived from a human pancreatic cancer cell line (SUIT-2) in nude mice. Clin Exp Metastasis 18: 561-571, 2000.

45. Westermarck J and Kahari VM: Regulation of matrix metalloproteinase expression in tumor invasion. FASEB J 13: 781-792, 1999.

46. van Dam H, Wilhelm D, Herr I, Steffen A, Herrlich P and Angel P ATF-2 is preferentially activated by stress-activated protein kinases to mediate c-jun induction in response to genotoxic agents. EMBO J 14: 1798-1811, 1995.

47. Zoumpourlis V, Papassava P, Linardopoulos S, Gillespie D, Balmain A and Pintzas A: High levels of phosphorylated c-Jun, Fra-1, Fra-2 and ATF-2 proteins correlate with malignant phenotypes in the multistage mouse skin carcinogenesis model. Oncogene 19: 4011-4021, 2000.

48. Khosravi-Far R, Campbell S, Rossman KL and Der CJ: Increasing complexity of Ras signal transduction: involvement of Rho family proteins. Adv Cancer Res 72: 57-107, 1998.

49. Hingorani SR and Tuveson DA: Ras redux: rethinking how and where Ras acts. Curr Opin Genet Dev 13: 6-13, 2003. 